\title{
Assessment of Nursing Care on Patient's Outcomes after Minimally Invasive and Conventional Cardiac Surgery
}

\author{
Sahar Ebrahim Abd- elmalek ${ }^{1}$, Mervat Anwar Abdel-Aziz ${ }^{2}$, Ghada Shalby khalaf ${ }^{3}$ \& Ahmed Mohamed Taha ${ }^{4}$ \\ 1. Specialist nursing at Orman Hospital, Assuit University. \\ 2. Assistant prof in Critical Care and emergency Nursing Department, Faculty of Nursing, Assuit University. \\ 3. Lecturer of Critical Care and emergency Nursing Department Faculty of Nursing, Assuit University. \\ 4. Lecturer of cardiothoracic surgery Faculty of medicine, Assuit University.
}

\begin{abstract}
In Minimally invasive heart surgery the patient experiences less pain and quicker recovery Aim: the study aimed to assess nursing care on patient's outcomes after minimally invasive and conventional cardiac surgery Patient and method. Design: descriptive research design was utilized in the study. Setting: this study was conducted in the postoperative ICU, Heart Assuit University Hospital. Sample: a convenience sample of 60 patients 30 minimally and 30 conventional. Four tools have been to utilized to gather the data, ToolI: patient's assessment sheet, Tool II: Intraoperative assessment sheet, Tool III: postoperative assessment sheet and Tool IV: patient outcome assessment sheet. Results: A number of clinical outcomes were significantly improved with minimally than conventional including pain assessment $30.8 \%$, quality of life91.27 \pm 3.03 , blood transfusion $35.1 \%$ and length of stay in intensive care unit.was3.04 \pm 0.74. Conclusions:assessment of nursing care founded that patients with minimally invasive associated with decreased bleeding, blood product transfusion, ventilation time, intensive care unit stay and less pain than conventional group. Recommendation: Establishing a standardized protocol for nursing care after cardiac surgery. Repeat this research on a large probability sample acquired from different geographical areas in Egypt.
\end{abstract}

\section{Keywords: Conventional Cardiac Surgery, Minimally Invasive Cardiac Surgery \& Patient's Outcomes.}

\section{Introduction}

The development of minimally invasive approaches in the cardiac surgical domain is indeed characterized by entirely specific challenges, i.e. the need to achieve both optimal myocardial protection and reliable extracorporeal perfusion (Speziale, et al., 2015).

Conventional cardiac surgery is performed via a median sternotomy; the sternum is divided completely from the sternal notch to the xiphisternum. The operation includes cardiopulmonary bypass established by siting cannulas in the right atrium and ascending aorta. In minimally invasive cardiac surgical procedures, there is less tissue trauma and the right atrium is not directly cannulated; conversely, cardiopulmonary bypass and aortic cross-clamp times are longer (Akowuahet al., 2017). Increasing interest is being shown in beating heart (off-pump) surgery because, compared with operations performed with cardiopulmonary bypass, off-pump surgery may be associated with decrease postoperative morbidity and reduce total costs. It appears to produce better results than conventional surgery in high- risk patient populations. (Chassot et al., 2004)

Minimally invasive heart surgery has been used as an alternative to traditional surgery for the following procedures (Coronary artery bypass graft, mitral valve repair, mitral valve replacement, aortic valve replacement, atrial septal defects and hybrid coronary revascularization).In Minimally invasive heart surgery the chest is not cut open, but rather small incisions are made in the right side of the chest, and the surgeon operates between the ribs. The patient experiences less pain and quicker recovery, while it also gives the surgeon a better view of some portions of the heart versus an open-heart surgery (Vishwas, et al., 2016).

Minimally invasive surgery confers many advantages over standard approaches derived largely from the reduced trauma to the chest wall tissues. The benefits of minimally invasive cardiac surgery include smaller incisions, smaller scars, reduced infection risk, less blood loss, less pain, shorter hospital stays. Stays after minimally invasive operations are from 3 to 5 days compared to 5 to 7 days for traditional sternotomy-based cardiac operations, fewer physical restrictions and shorter recovery time (Salgado, et al., 2016).

Immediate post-operative care the critical care nurse should be present in the ICU when the patient arrives from the operating room to receive a sign-over from the anesthesiologist and the cardiac surgical team. 
During this period the ICU nurses will be transferring the patient to the ICU monitors and checking all lines and infusions. The nurse will then do the initial set of hemodynamic reading. The respiratory technician will place the patient on a ventilator. Unless the patient is unstable it is the best to stay out of the way of the nurses during this period and wait until they are finished with their assessment before examining the patient. (Mc Gill, 2017)

\section{Aim of the study}

To assess nursing care on patient's outcomes after minimally invasive and conventional cardiac surgery.

\section{Significance of the study}

Cardiovascular disease (CVD) is the number one cause of death worldwide and therefore, the major contributor to the burden of disease. In 2008, $30 \%$ of all global deaths (17.3 million) were attributed to CVD. Of these deaths, an estimated 7.3 million were due to coronary artery disease. CVD results from blockage of the coronary arteries by atherothrombosis, which is regularly treated with minimally or non-minimally invasive off- or onpump cardiothoracic surgery (Moza, 2015).

During the year of 2016, the number of patients admitted for cardiac surgery at Assiut University cardiac center was 300 cases.

\section{Research question}

What is the nursing assessment of nursing on patient's outcomes after minimally invasive versus conventional cardiac surgery?

\section{Operational definitions}

\section{Minimally invasivecardiac surgery}

A term used to imply cardiac surgery done with small incisions or with endoscopic procedures. These include parasternal, rightsided partial sternotomy and lower half sternotomy (Nathaniel \& Michael, 2016). Minimally invasive heart surgery, the chest is not cut open, but rather small incisions are made in the right side of the chest, and the surgeon operates between the ribs. (Vishwas, et al, 2016).

\section{Conventional cardiac surgery}

A type of incision in the center of the chest that allows access to the heart.

Conventional heart surgery is typically performed on an open heart, therefore requiring both sternotomy (separation of the breastbone) and cardiopulmonary bypass (a heart-lung machine) as it requires the heart to be stopped.

\section{Research design}

Descriptive study was utilized to conduct the aim of this study.

\section{Setting of the study}

The study was conducted at Assuit university cardiac center in post-operative intensive care unit .consist 12 beds for patients.

\section{Sample}

A convenience sample of 60 uncomplicated adult patient male and female underwent cardiac surgery who are admitted to postoperative ICU, this sample was assigned randomly into two groups 30 minimally and 30 conventional.

\section{Pilot study}

A pilot study was carried out before starting of data collection to test the feasibility, applicability and the clarity of the study tools on $10 \%$ (6 patients) of the sample and the necessary modifications were done. The pilot study patients were included in the study sample.

The overall reliability of the tools was tested using $(\alpha)$ Cronbach's test (.90) for the pilot study results.

\section{Exclusion criteria}

Pregnancy, have infective endocarditis, a hematological condition that would affect participation and documented chest wall deformities Tools

Four tools were used to collect the data in this study and developed by the reviewing of related literature

Tool one: "preoperative patient's assessment sheet"

This tool developed by the researcher to assess the patient conditions to form base line data

Part I:-Assessment of the demographic patient's profile that included Patient's sex and age.

Part II: Assessment of the patient's clinical data which included medical diagnosis and past history

Tool two: "Intraoperative assessment sheet

This tool developed by the researcher to assess the patient conditions during the operation. (Scott, et al., 2015)

-Ischemic time, bypass time, and operation time, intraoperative blood transfusion.

Tool three: postoperative assessment sheet

This tool developed by the researcher to assess the patient conditions in the post-operative period. Included two parts (cheng, et al., 2011)

Part I: "visual analog scale for pain (Clark, et al., 2009)

\begin{tabular}{|l|c|}
\hline \multicolumn{1}{|c|}{ Item } & Score \\
\hline $0-3$ & Mild \\
\hline $4-6$ & Moderate \\
\hline $7-10$ & Severe \\
\hline score of 0 (no pain) $*$ score of 10 (worst \\
imaginable pain ) \\
Part II: "Quality of life (EuroQoL EQ-5D-3L)
\end{tabular}

(adopted to Van, 2015) 


\begin{tabular}{|c|c|}
\hline Item & Scale \\
\hline Mobility & $\begin{array}{l}\text { 1-no problem } 2 \text { - some } \\
\text { problem 3-extrem problem }\end{array}$ \\
\hline Self Care & $\begin{array}{l}\text { 1-no problem 2- some } \\
\text { problem 3-extrem problem }\end{array}$ \\
\hline Activities & $\begin{array}{l}\text { 1-no problem } 2-\text { some } \\
\text { problem 3-extrem problem }\end{array}$ \\
\hline Pain & $\begin{array}{l}\text { 1-no problem } 2-\text { some } \\
\text { problem 3-extrem problem }\end{array}$ \\
\hline Anxiety & $\begin{array}{l}\text { 1-no problem 2- some } \\
\text { problem 3-extrem problem }\end{array}$ \\
\hline
\end{tabular}

Tool four "patient outcome assessment sheet

This tool developed by the researcher to assess the patient outcomes included:

(cheng, et al., 2011)

Part I: Time to first mobilization: defined as walking independently

Part II: Time to extubation: total number of hours of intubation (to account for re-intubation) and need for analgesia after extubation

Part III: ICU stay (the period that the patient spend in the ICU)

Part IV: Wound infection and requirement for antibiotics.

Part V: Postoperative bleeding and blood transfusion: Blood loss during the first 12 hours after surgery will be recorded. The blood transfusion requirement during the first 48 hours after surgery in all cases will be recorded.

Method of Data collection

\section{Preparatory phase}

- Approval to conduct the study was obtained from the hospital responsible authorities in the postoperative cardiac intensive care unit after explanation of the aim of the study.

- Informed consent was taken from the head of cardiac intensive care unit as well as the patients to carry out this study.

- The tools were developed by the researcher based on the relevant literature reviewing.

- The developed tools was tested for the content validity by selected juries of critical care medical and nursing professionals to assess the clarity, feasibility and applicability.

- The tools were tested for clarity and reliability using $(\alpha)$ Cronbach's test (.90) for the pilot study results.

- A pilot study of six patients was carried out in order to assess the clarity and applicability of the tools.

\section{Ethical consideration}

1. Research proposal was approved from Ethical committee in the Faculty of nursing.
2. There is no risk for study subject during application of the research.

3. The study followed the common ethical principles in clinical research.

4. Written consent was obtained from patients or guidance that are willing to participate in the study after explaining the nature and the purpose of the study.

5. Confidentiality and anonymity were assured.

6. Study subject have the right to refuse to participate and or withdraw from the study without any rational any time.

7. Study subject privacy was considered during collection of data.

\section{Field work}

Sampling was started from the first of April 2018 to March 2019

\section{Implementation phase}

- The researcher assessed baseline hemodynamic status for all patients (preoperative, during operation and until discharge from ICU)

- The researcher assessed ischemic time, bypass time and duration of operation for all patients

- Pain was assessed by visual analog scale. Pain is also assessed post-operatively (daily from postoperative day 2 until the patient is deemed 'fit for discharge'), and at follow-up (2 and 6 weeks following discharge).

- Occurrence of bleeding and need for blood transfusion were assessed for all patients.

- Quality of life is assessed for each patient by using the EuroQoL EQ-5D-3L questionnaires at baseline. When the patient was physically unable to complete the questionnaires, the assessment was performed over the telephone; Questionnaires are repeated at 2 weeks and 6 weeks following discharge from hospital.

- The researcher assessed wound infection, time of extubation, and need for analgesia after extubation for all patients

- The researcher assesses length of ICU, mortality for all patients.

\section{Statistical analysis}

The collected data were coded then transformed into coding sheets. The results were checked. Then, the data were entered into statistical packing for social science (SPSS) version (20) using personal computer. Output drafts were checked against the revised coded data for typing and spelling mistakes. Finally, analysis and interpretation of data were conducted. Descriptive statistics including frequency, distribution, mean and standard deviation were used to describe different characteristics. P-value is considered significant when $\mathrm{p}<0.0$. 


\section{Results}

Table (1): Distribution of Sociodemographic data of Studies groups (Conventional, Minimal).

\begin{tabular}{|c|c|c|c|c|c|}
\hline & \multicolumn{5}{|c|}{ Type of operation } \\
\hline & \multicolumn{2}{|c|}{ Conventional(n=30) } & \multicolumn{2}{|c|}{$\operatorname{Minimal}(\mathbf{n}=30)$} & \multirow{2}{*}{ P. value } \\
\hline & n. & $\%$ & n. & $\%$ & \\
\hline \multicolumn{6}{|l|}{ Age group } \\
\hline $19<30$ years & 5 & 16.70 & 6 & 20.0 & \multirow{4}{*}{0.846} \\
\hline $30<40$ years & 6 & 20.00 & 7 & 23.30 & \\
\hline $40<50$ years & 9 & 30.00 & 6 & 20.00 & \\
\hline more than 50 years & 10 & 33.30 & 11 & 36.70 & \\
\hline Mean \pm SD & \multicolumn{2}{|c|}{$43.67 \pm 11.78$} & \multicolumn{2}{|c|}{$42.2 \pm 13.04$} & 0.649 \\
\hline \multicolumn{6}{|l|}{ Sex } \\
\hline Male & 14 & 46.7 & 14 & 46.67 & \multirow{2}{*}{1.000} \\
\hline Female & 16 & 53.3 & 16 & 53.33 & \\
\hline \multicolumn{6}{|l|}{ level education } \\
\hline Read \& write & 6 & 20.00 & 8 & 26.67 & \multirow{5}{*}{0.090} \\
\hline Primary & 2 & 6.67 & 0 & 0.00 & \\
\hline Preparatory & 6 & 20.00 & 2 & 6.67 & \\
\hline Secondary & 14 & 46.67 & 12 & 40.00 & \\
\hline University & 2 & 6.67 & 8 & 26.67 & \\
\hline \multicolumn{6}{|l|}{ marital state } \\
\hline Single & 4 & 13.33 & 5 & 16.67 & \multirow{2}{*}{1.000} \\
\hline Married & 26 & 86.67 & 25 & 83.33 & \\
\hline
\end{tabular}

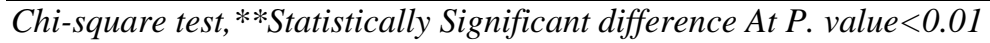

Table (2): Distribuation of Medical data of Studies groups (Conventional, Minimal).

\begin{tabular}{|c|c|c|c|c|c|}
\hline & \multicolumn{5}{|c|}{ Type of operation } \\
\hline & \multicolumn{2}{|c|}{ Conventional $(\mathrm{n}=30)$} & \multicolumn{2}{|c|}{$\operatorname{Minimal}(\mathbf{n}=30)$} & \multirow{2}{*}{ P. value } \\
\hline & n. & $\%$ & n. & $\%$ & \\
\hline \multicolumn{6}{|l|}{ medical diagnosis } \\
\hline Mitral valve Stenosis & 0 & 0.0 & 2 & 6.67 & \multirow{9}{*}{$0.039 *$} \\
\hline Aortic valve replacement & 4 & 13.3 & 0 & 0.00 & \\
\hline Atrial septal defect & 1 & 3.3 & 1 & 3.33 & \\
\hline Coronary artery bypass graft & 11 & 36.7 & 11 & 36.67 & \\
\hline Double valve replacement & 4 & 13.3 & 0 & 0.00 & \\
\hline mitral valve replacement & 9 & 30 & 11 & 36.6 & \\
\hline sever pulmonary stenosis & 1 & 3.3 & 0 & 0.00 & \\
\hline Tricuspid Value replacement & 0 & 0.0 & 2 & 6.67 & \\
\hline Ventricle septal defect & 0 & 0.0 & 3 & 10.00 & \\
\hline \multicolumn{6}{|c|}{ past history risk factor for cardiac disease } \\
\hline Non & 12 & 40.00 & 11 & 36.67 & \multirow{5}{*}{0.879} \\
\hline Hypertension & 0 & 0.00 & 1 & 3.33 & \\
\hline Diabetes & 4 & 13.33 & 5 & 16.67 & \\
\hline Rheumatic Heart & 13 & 43.33 & 12 & 40.00 & \\
\hline Diabetes \& Hypertension & 1 & 3.33 & 1 & 3.33 & \\
\hline
\end{tabular}

Chi-square test $*$ Statistically Significant difference At P. value $<0.05$.independent $T$ - test $*$ Statistically Significant difference At P. value $<0.05$ 
Table (3): Distribuation of intraoperative data and blood transfusion For Studies groups (Conventional, Minimal).

\begin{tabular}{|c|c|c|c|c|c|}
\hline & \multicolumn{5}{|c|}{ Type of operation } \\
\hline & \multicolumn{2}{|c|}{ Conventional(n=30) } & \multicolumn{2}{|c|}{$\operatorname{Minimal}(\mathbf{n}=30)$} & \multirow{2}{*}{ P. value } \\
\hline & n. & $\%$ & n. & $\%$ & \\
\hline operation time & \multicolumn{2}{|c|}{$7.07 \pm 1.08$} & \multicolumn{2}{|c|}{$6.2 \pm 0.61$} & $<0.00 * *$ \\
\hline Ischemic time & \multicolumn{2}{|c|}{$83.62 \pm 30.75$} & \multicolumn{2}{|c|}{$85.71 \pm 15.43$} & 0.795 \\
\hline bypass time & \multicolumn{2}{|c|}{$150.97 \pm 151.94$} & \multicolumn{2}{|c|}{$117 \pm 22.61$} & 0.367 \\
\hline \multicolumn{6}{|c|}{ Blood transfusion } \\
\hline Plasma & 27 & 90.0 & 24 & 80.0 & 0.469 \\
\hline Mean \pm SD & \multicolumn{2}{|c|}{$675.93 \pm 167.2$} & \multicolumn{2}{|c|}{$562.2 \pm 132.9$} & $0.010 *$ \\
\hline Blood & 17 & 56.7 & 13 & 43.3 & 0.438 \\
\hline Mean \pm SD & \multicolumn{2}{|c|}{$676.4 \pm 146.9$} & \multicolumn{2}{|c|}{$596.16 \pm 162.61$} & 0.175 \\
\hline
\end{tabular}

Chi-square test *Statistically Significant difference At P. value <0.05, **Statistically Significant difference At P. value $<0.01$

Table (4): Relationship Between Studies groups According topostoperativebleeding and blood transfusion

\begin{tabular}{|c|c|c|c|c|c|}
\hline & \multicolumn{2}{|c|}{ Conventional $(n=30)$} & \multicolumn{2}{|c|}{$\operatorname{Minimal}(n=30)$} & \multirow{2}{*}{ P. value } \\
\hline & n. & $\%$ & n. & $\%$ & \\
\hline \multicolumn{6}{|c|}{ post-operative bleeding } \\
\hline Yes & 8 & 26.7 & 1 & 3.3 & \multirow{2}{*}{$0.026 *$} \\
\hline No & 22 & 73.3 & 29 & 96.7 & \\
\hline \multicolumn{6}{|l|}{ Blood transfusion } \\
\hline \multicolumn{6}{|l|}{ Day of operation } \\
\hline Plasma(No.patient) & 19 & 63.3 & 11 & 36.7 & 0.070 \\
\hline Amount & \multicolumn{2}{|c|}{$465.8 \pm 214.1$} & \multicolumn{2}{|c|}{$350.0 \pm 187$} & 0.135 \\
\hline Blood(No.patient) & 20 & 66.7 & 11 & 36.7 & $0.038 *$ \\
\hline Amount & \multicolumn{2}{|c|}{$447.5 \pm 240.3$} & \multicolumn{2}{|c|}{$363.6 \pm 130.6$} & 0.218 \\
\hline \multicolumn{6}{|l|}{ Day1Post Surgery } \\
\hline Plasma(No.patient) & 4 & 13.3 & 2 & 6.7 & 0.667 \\
\hline Amount & \multicolumn{2}{|c|}{$500.0 \pm 0$} & \multicolumn{2}{|c|}{$250 \pm 0.0$} & - \\
\hline Blood(No.patient) & 10 & 33.3 & 5 & 16.7 & 0.233 \\
\hline Amount & \multicolumn{2}{|c|}{$370.0 \pm 137.8$} & \multicolumn{2}{|c|}{$350.0 \pm 136.9$} & 0.795 \\
\hline
\end{tabular}

*Statistically Significant difference At P. value $<0.05$,

Table (5): Comparison between Studies groups According to Mechanical ventilation Parameters.

\begin{tabular}{|c|c|c|c|c|c|}
\hline \multirow{2}{*}{ Day of operation } & \multicolumn{2}{|c|}{ Conventional $(n=30)$} & \multicolumn{2}{|c|}{$\operatorname{Minimal}(\mathbf{n}=30)$} & \multirow{2}{*}{ P. value } \\
\hline & \multicolumn{2}{|c|}{ Mean \pm SD } & \multicolumn{2}{|c|}{ Mean \pm SD } & \\
\hline Rate & \multicolumn{2}{|c|}{$14.07 \pm 1.34$} & \multicolumn{2}{|c|}{$13.47 \pm 1.17$} & 0.069 \\
\hline Fio2 (fraction inspiratory oxygen) & \multicolumn{2}{|c|}{$61.67 \pm 10.85$} & \multicolumn{2}{|c|}{$59.67 \pm 9.64$} & 0.454 \\
\hline Peep (positive end expiratory pressure) & \multicolumn{2}{|c|}{$6.07 \pm 3.72$} & \multicolumn{2}{|c|}{$5.1 \pm 0.55$} & 0.165 \\
\hline Ps (pressure support) & \multicolumn{2}{|c|}{$9.03 \pm 1.13$} & \multicolumn{2}{|c|}{$8.47 \pm 0.86$} & $0.033^{*}$ \\
\hline duration of mechanical ventilation & \multicolumn{2}{|c|}{$3.43 \pm 1.22$} & \multicolumn{2}{|c|}{$2.4 \pm 0.72$} & $<0.001 * *$ \\
\hline Vt (tidal volume) & \multicolumn{2}{|c|}{$466.67 \pm 42.21$} & \multicolumn{2}{|c|}{$473.33 \pm 59.79$} & 0.620 \\
\hline mode & $\mathrm{No}$ & $\%$ & No & $\%$ & \\
\hline SIMV & 30 & 100 & 30 & 100 & - \\
\hline \multicolumn{6}{|l|}{ re intubation } \\
\hline Yes & 6 & 20.0 & 0 & 0.0 & \multirow{2}{*}{$0.031 *$} \\
\hline No & 24 & 80.0 & 30 & 100.0 & \\
\hline
\end{tabular}




\begin{tabular}{|c|c|c|c|c|c|}
\hline \multirow{2}{*}{ Day of operation } & \multirow{2}{*}{\multicolumn{2}{|c|}{$\begin{array}{c}\text { Conventional }(\mathrm{n}=30) \\
\text { Mean } \pm \text { SD }\end{array}$}} & \multirow{2}{*}{\multicolumn{2}{|c|}{$\frac{\operatorname{Minimal}(\mathbf{n}=30)}{\operatorname{Mean} \pm \text { SD }}$}} & \multirow{2}{*}{ P. value } \\
\hline & & & & & \\
\hline \multicolumn{6}{|l|}{ need for analgesia after extubation } \\
\hline Yes & 25 & 83.3 & 17 & 56.67 & \multirow{2}{*}{$0.047 *$} \\
\hline No & 5 & 16.7 & 13 & 43.33 & \\
\hline \multicolumn{6}{|l|}{ Name of analgesia } \\
\hline epicotil & 3 & 10.0 & 4 & 13.3 & \multirow{3}{*}{0.170} \\
\hline ketolac & 17 & 56.7 & 13 & 43.3 & \\
\hline Lidocaine & 0 & 0.0 & 1 & 3.3 & \\
\hline Nalfon & 2 & 6.7 & 0 & 0.0 & \\
\hline ICU stay & \multicolumn{2}{|c|}{$3.66 \pm 0.61$} & \multicolumn{2}{|c|}{$3.04 \pm 0.74$} & $<0.001 * *$ \\
\hline
\end{tabular}

Chi-square test *Statistically Significant difference At P. value $<0.05$,

*Statistically Significant difference At P. value $<0.05$, **Statistically Significant difference At P. value $<0.01$

Table (6): Relationship Between Studies groups According to Pain assessment.

\begin{tabular}{|c|c|c|c|c|c|}
\hline & \multicolumn{2}{|c|}{ Conventional(n=30) } & \multicolumn{2}{|c|}{$\operatorname{Minimal}(\mathbf{n}=30)$} & \multirow{2}{*}{ P. value } \\
\hline & n. & $\%$ & n. & $\%$ & \\
\hline \multicolumn{6}{|c|}{ Day of operation } \\
\hline Mild & 3 & 6.9 & 4 & 7.7 & \multirow{3}{*}{$<0.001 * *$} \\
\hline Moderate & 2 & 6.9 & 18 & 61.5 & \\
\hline Sever & 25 & 86.2 & 8 & 30.8 & \\
\hline \multicolumn{6}{|l|}{ Day1 } \\
\hline Mild & 2 & 6.7 & 15 & 50.0 & \multirow{3}{*}{$0.001 * *$} \\
\hline Moderate & 21 & 70.0 & 9 & 30.0 & \\
\hline Sever & 7 & 23.3 & 6 & 20.0 & \\
\hline Day2 & $n=28$ & $\%$ & $\mathrm{n}=\mathbf{2 5}$ & $\%$ & \\
\hline Mild & 7 & 25.0 & 18 & 72.0 & \multirow{3}{*}{$0.003 * *$} \\
\hline Moderate & 20 & 71.4 & 7 & 28.0 & \\
\hline Sever & 1 & 3.6 & 0 & 0.0 & \\
\hline Day3 & $n=18$ & $\%$ & $n=7$ & $\%$ & \\
\hline Mild & 15 & 83.3 & 7 & 100.0 & \multirow{3}{*}{0.515} \\
\hline Moderate & 2 & 11.1 & 0 & 0.0 & \\
\hline Sever & 1 & 5.6 & 0 & 0.0 & \\
\hline Day4 & $n=3$ & $\%$ & $n=1$ & $\%$ & \\
\hline Mild & 2 & 66.7 & 1 & 100.0 & \multirow{2}{*}{0.505} \\
\hline Moderate & 1 & 33.3 & 0 & 0.0 & \\
\hline
\end{tabular}

Chi-square test **Statistically Significant difference At P. value $<0.01$,

Note:

Number of patient discharge in day 2 (5 minimally - 2 conventional)

Number of patient discharge in day3 (23 minimally- 12 conventional)

Number of patient discharge in day 4 (29 minimally - 27 conventional) 
Table (7): Relationship between Studies groups According to quality of life and VAS 2 week Post Surgery.

\begin{tabular}{|c|c|c|c|c|c|}
\hline \multirow{2}{*}{2 Weak post surgery } & \multicolumn{2}{|c|}{ Conventional $(n=30)$} & \multicolumn{2}{|c|}{$\operatorname{Minimal}(\mathbf{n}=30)$} & \multirow{2}{*}{ P. value } \\
\hline & n. & $\%$ & n. & $\%$ & \\
\hline \multicolumn{6}{|l|}{ Mobility2week } \\
\hline No problem & 1 & 3.3 & 12 & 40.0 & \multirow{3}{*}{$0.001 * *$} \\
\hline Some problem & 26 & 86.7 & 18 & 60.0 & \\
\hline Extreem problem & 3 & 10.0 & 0 & 0.0 & \\
\hline \multicolumn{6}{|l|}{ SelfCare2w } \\
\hline No problem & 1 & 3.3 & 9 & 30.0 & \multirow{3}{*}{$0.005 * *$} \\
\hline Some problem & 25 & 83.3 & 21 & 70.0 & \\
\hline Extreem problem & 4 & 13.3 & 0 & 0.0 & \\
\hline \multicolumn{6}{|l|}{ Activities2w } \\
\hline No problem & 1 & 3.3 & 9 & 30.0 & \multirow{3}{*}{$0.010 *$} \\
\hline Some problem & 27 & 90.0 & 21 & 70.0 & \\
\hline Extreem problem & 2 & 6.7 & 0 & 0.0 & \\
\hline \multicolumn{6}{|l|}{ Pain2w } \\
\hline No problem & 1 & 3.3 & 10 & 33.3 & \multirow{2}{*}{$0.003 * *$} \\
\hline Some problem & 29 & 96.7 & 20 & 66.7 & \\
\hline \multicolumn{6}{|l|}{ Anxiety2w } \\
\hline No problem & 1 & 3.3 & 5 & 16.7 & \multirow{2}{*}{0.085} \\
\hline Some problem & 29 & 96.7 & 25 & 83.3 & \\
\hline scale2w & \multicolumn{2}{|c|}{$79.33 \pm 5.68$} & \multicolumn{2}{|c|}{$81.5 \pm 8.11$} & 0.236 \\
\hline
\end{tabular}

Chi-square test *Statistically Significant difference At P. value $<0.05$, **Statistically Significant difference At P. value $<0.01$

Table (8): Relationship between Studies groups According to quality of life and VAS 6 week Post Surgery.

\begin{tabular}{|c|c|c|c|c|c|}
\hline \multirow{2}{*}{6 Weak post surgery } & \multicolumn{2}{|c|}{ Conventional $(n=30)$} & \multicolumn{2}{|c|}{$\operatorname{Minimal}(n=30)$} & \multirow{2}{*}{ P. value } \\
\hline & n. & $\%$ & n. & $\%$ & \\
\hline \multicolumn{6}{|l|}{ Mobility } \\
\hline No problem & 30 & 100.0 & 30 & 100.0 & - \\
\hline \multicolumn{6}{|l|}{ SelfCare } \\
\hline No problem & 30 & 100.0 & 30 & 100.0 & - \\
\hline \multicolumn{6}{|l|}{ Activities } \\
\hline No problem & 9 & 30.0 & 29 & 96.7 & \multirow{2}{*}{$<0.001 * *$} \\
\hline Some problem & 21 & 70.0 & 0 & 0.0 & \\
\hline \multicolumn{6}{|l|}{ Pain } \\
\hline No problem & 22 & 73.3 & 30 & 100.0 & \multirow{2}{*}{$<0.001 * * *$} \\
\hline Some problem & 8 & 26.7 & 0 & 0.0 & \\
\hline \multicolumn{6}{|l|}{ Anxiety } \\
\hline No problem & 19 & 63.3 & 30 & 100.0 & \multirow{2}{*}{$<0.001 * *$} \\
\hline Some problem & 11 & 36.7 & 0 & 0.0 & \\
\hline scale6w & \multicolumn{2}{|c|}{$88.17 \pm 3.34$} & \multicolumn{2}{|c|}{$91.27 \pm 3.03$} & $<0.001 * *$ \\
\hline
\end{tabular}

Chi-square test $* *$ Statistically Significant difference At P. value $<0.01$ 
Table (9): Assessment of Nausea and vomiting for studies groups.

\begin{tabular}{|c|c|c|c|c|c|}
\hline & \multicolumn{2}{|c|}{ Conventional $(n=30)$} & \multicolumn{2}{|c|}{$\operatorname{Minimal}(\mathbf{n}=30)$} & \multirow{2}{*}{ P. value } \\
\hline & n. & $\%$ & n. & $\%$ & \\
\hline Nausea (yes ) & 13 & 43.3 & 2 & 6.9 & $0022 * *$ \\
\hline Frequency $($ Mean \pm SD $)$ & \multicolumn{2}{|c|}{$2.69 \pm 0.63$} & \multicolumn{2}{|c|}{$1.67 \pm 0.58$} & $0.0 \angle 2 \cdots$ \\
\hline Vomiting ( yes) & 11 & 36.7 & 4 & 13.8 & 0.073 \\
\hline Frequency (Mean \pm SD ) & \multicolumn{2}{|c|}{$1.82 \pm 0.6$} & \multicolumn{2}{|c|}{$1.75 \pm 1.5$} & 0.898 \\
\hline
\end{tabular}

independent T- test ${ }^{*}$ Statistically Significant difference At P. value $<0.05$,

Chi-square test $*$ Statistically Significant difference At P. value $<0.05$.

Table (1): Shows the sociodemographiccharacteristics of the two groups. Regarding to the age it was found that the means \pm SD in conventional group was $43.67 \pm 11.78$, the means $\pm \mathrm{SD}$ in minimally group was $42.2 \pm 13.04$. Regarding to the sex it was found that males and females were equal in both group. The majority of both groups were educated and having secondary degree it was $51.9 \%$ in conventional and $42.86 \%$ in minimal for marital status the highest percentage were married it was $89.7 \%$ in conventional and $86.2 \%$ in minimally .

Table (2): Shows the medical data for both groups. Regarding to medical diagnosis it was found that the major medical diagnosis in both group (conventional and in minimally) were CABG, MVR, DVR, AVR, VSD, MVS, TVR, ASD .regarding to the significance, there were statistical difference between both groups. For the past history and risk factor of cardiac disease the results revealed that the majority of patients in both groups had no past history, while (43.3\%) of the conventional had rheumatic heart and $(40 \%)$ of the minimally also rheumatic heart. There was no statistical difference between both groups.

Table (3): Shows intraoperative assessment of both groups. . In the relation between two groups according the operation times the results revealed that the means \pm SD in conventional group was $7.07 \pm 1.08$, and the means \pm SD in minimally invasive was $6.2 \pm 0.61$. There were statistical differences between both groups. For ischemic time and bypass time there were no statistical difference between both groups .regarding to plasma it was found that the major of all patients that had taken plasma intraoperation were $90 \%$ in conventional , and $64.9 \%$ in minimally .

Table (4): Shows the relation between both groups For post-operative bleeding it was found that the major of the patients had no post-operative bleeding only $(26.7 \%)$ of the conventional group had bleeding while in minimally (3.3) . regarding to significance there were statistical significance difference between both groups. regarding to patients that had taken plasma at the day of operation were $48.7 \%$ in conventional, and $50 \%$ in minimally . at the day 1patients that had taken plasma were $28.6 \%$ in conventional , and $28.6 \%$ in minimally . regarding to significance there were statistical significance difference between both groups during intraoperation . Regarding to blood it was found that the major of all patients that had taken blood intraoperation were $38.6 \%$ in conventional, and $35.1 \%$ in minimally .while patients that had taken blood at the day of operation were $51.3 \%$ in conventional .

Table (5): Shows that all patients of both groups were on SIMV mode .there were significance difference between both groups as regard to re intubation, $20 \%$ in conventional while in minimally $0.0 \%$. There were significant difference between both groups as regard to duration of mechanical ventilation .Regarding to the need for analgesia after extubation the result revealed that the majority of patients in both groups had taken analgesia, $83.3 \%$ in conventional, and $56.6 \%$ in minimally. Regarding to the intensive care unit stay it was found that the means $\pm \mathrm{SD}$ in conventional group was $3.66 \pm 0.61$ and the means $\pm \mathrm{SD}$ in minimally invasive was3.04 \pm 0.74 . Therewere statistical differences between both groups.

Table (6): This table demonstrates that, there was statistical significance difference between both groups according to pain assessment at day of operation, day1and day $2.86 .2 \%$ in conventional had sever pain, and $30.8 \%$ in minimally at day of operation.

Table (7): This table show that, assessment of quality of life 2 weeks after surgery were statistical significant at mobility, self care, activities and pain. whilenon statistical significant difference as regard to anxiety .

Table (8): This table show that, assessment of quality of life 6 weeks after surgery were statistical significant at activities, pain and anxiety. Regarding to mobility and self care all patients of both groups had no problem. as regard EQ VAS scale 6 weeks after surgery. The highest mean was $91.27 \pm 3.03$ in minimally, and in conventional was $88.17 \pm 3.34$.

Table (9): Enumerate that assessment of nausea of both groups were significant difference $43.3 \%$ in 
conventional and $6.9 \%$ in minimally while the mean score was $2.69 \pm 0.63$ in conventional , $1.67 \pm 0.58$ in minimally as regard to frequency of nausea

\section{Discussion}

Cardiac surgery is the specialty of medicine concerning the surgical treatment of pathologies related to the heart and thoracic aorta. The spectrum of modern cardiac surgery can be understood by its history beginning at the end of the 19th century. Since then cardiac surgery developed through the work of numerous dedicated surgeons offering more and more treatments for diverse cardiac pathology. This development is still ongoing today. Surgical revascularization is one option to relieve ischemic heart disease with complicated atherosclerosis (David \& Lawrence, 2017).

Based on the results of this study, the mean age of the group who perform minimal cardiac surgery was younger than patients of the group who done conventional cardiac surgery with no statistically significant difference between both groups as regard to age. And this result is in the same line with the (Svensson, et al., 2015) who noticed that the patient who underwent minimally invasive cardiac surgery were younger than the patient underwent conventional surgery but (Yamada, et al., 2013) disagree with this study and show that the mean \pm SD of the minimally invasive cardiac surgery patient is higher than conventional patients.

As regard to sex, this study revealed that there is no significant difference among both groups and this result is confirmed by (Ahmed, et al., 2018) who noticed that the gender has no effect on the choice of cardiac surgery type.

The present study demonstrated that there was a highly significant difference between both groups regarding to the level of education and this result agree with (Bjørnnes, et al., 2018) who revealed that increasing the level of education help for seeking medical help and early detection and management of cardiac disease.

As for marital status, the present study shows no significant difference between both groups in relation to marital status and this result is in divorce with the results of (Bjørnnes, et al., 2018) who found that the majority of patients underwent the conventional cardiac surgery were married.

Concerning the results of current study, the most common diagnosis for cardiac surgery is coronary artery bypass graft and mitral valve replacement with a highly significant difference between both groups and this result disagree with (Svensson, et al., 2015) who found that the most common indication for cardiac surgery were degenerative changes of the cardiac valves and ischemic heart diseases.

Regarding to past history of cardiac diseases the results supported by (Yamada, et al., 2013) who showed that diabetes mellitus or hypertension not affect the type of cardiac surgery. but these results confused with (Cakir, et al., 2018)who showed that the rheumatic heart disease, diabetes mellitus and hypertension are most common noncardiac causes for cardiac surgery.

The present study denoted that the patient underwent minimally invasive surgery used pain analgesia by level lower than patient had conventional cardiac surgery this may be due to the small incision of the wound and this result agreed with the results of (Kenan, et al., 2017) who found a significant difference related to analgesic usage after extubation. According to the total bypass time there was significant difference between the both groups this result matches with the results of (Shawky, et al., 2016)but disagree with (Ahmed, et al., 2018) who noticed that there was significant difference in relation to the bypass time between the minimal invasive and the conventional cardiac surgery.

The total operation time of the minimally invasive procedures is generally longer than the time required for conventional surgery and this may be due to the new experiences in this minimally invasive surgery and the narrow field of MIMVS and this result is supported by (Shawky, et al., 2016) \& (Mark, et al., 2016) who revealed a highly significant difference between both groups regarding to total operation time.

The present study demonstrated that the postoperative bleeding occurs at higher rates in the group underwent conventional surgery than the patients had minimal invasive cardiac surgery and this may be due to less traumatic nature of the minimally invasive and this result approved by (Jitumoni, et al., 2017) who demonstrate that there was a highly significant difference between both groups related to postoperative blood loss.

The present study revealed that the length of ICU stay of the minimally invasive group is shorter than the period spent in the ICU for the conventional group and this result is in line with (Thomas, et al., 2015) who showed a significant difference related to length of ICU stay but these results disagree with (Mark, et al., 2016) who noticed that there was no significant difference related to postoperative length of stay.

Based on the results of this study, there was a significant difference between both groups related to intraoperative blood transfusion and this result agreed with (Saif, et al., 2018) who found that The 
minimally invasive cardiac surgery patients had a lower average incidence of intra and postoperative transfusion of blood.

The present study reported that the total amount of blood transfused postoperatively for conventional surgery is higher than which transfused to patient underwent minimally invasive surgery and this result is in the same line with (Lars, et al., 2014) who found a significant difference in relation to the blood transfusion after operation.

Concerning the time of ventilation, the present study revealed that the time of positive pressure ventilation in minimally invasive group is clearly shortly than the time for conventional group and this result matches with the result of (Ward, et al., 2013) who noticed that there was a highly significant difference in relation to the ventilatory time.

As regard to the need for reintubation the present study reported that about quarter of the conventional group were reintubated and this result supported by findings of the(Shawky, et al, 2016)who reported a significant difference related to the need for reintubation between both groups but, these finding disagree with

(Michael, et al., 2016) who demonstrate no significant difference regarding reintubation for both groups.

Pain levels for minimally invasive surgery is less intensive compared to conventional group and about two thirds of the highly tolerated pain level were moderated at the second day after operation so this result agreed with the results of (Thomas, et al., 2015) and (Shawky, et al., 2016) who noticed that there was a significant difference related to pain between the both groups.

During assessment period after surgery by 2 weeks, the current study noticed that the minimal invasive group were adapted to the postoperative status more than the conventional group as they mobile easier, having lower level of pain and anxiety and about two thirds return to their normal activities with some problems and after 6 weeks, the significant difference was related to pain, anxiety and activities these results is confirmed with the results of (Schweikert, et al., 2016) who noticed a statistical difference among the studied groups EQ-5D health questionnaire.

When comparing the EQ-VAS between the data of the $2^{\text {nd }}$ and $6^{\text {th }}$ week after the surgery, the present study demonstrated that there was statistical difference between both groups related to the $6^{\text {th }}$ week postoperatively.

The present study assessed the gastrointestinal tract and reported that the most common GIT complications after cardiac surgery was nausea with significant difference between minimal invasive and conventional cardiac surgery but (Michael, et al., 2016) disagree with these results as they found that the most common GIT complications was gastric bleeding and (Paul, et al., 2015) reported that there was no statistically significant difference in relation to GIT complications and cardiac surgery.

\section{Conclusion}

assessment of nursing care founded that patients with minimally invasive associated with decreased bleeding, blood product transfusion, ventilation time, intensive care unit stay and less pain than conventional group.

\section{Recommendation}

1. Establishing a standardized protocol for nursing care after cardiac surgery.

2. Repeat this research on a large probability sample acquired from different geographical areas in Egypt.

\section{References}

1. Ahmed L., Ali H., Medhat R., \& Mohamed B., (2018): Early outcome of thoracoscopic minimally invasive versus conventional mitral valve surgery for mitral valve diseases, Menoufia Medical Journal,31(4):1397-1401.

2. Akowuah E., Andrew T., Goodwin, W., Andrew Owens, Helen C., Hancock, Rebecca Maier, Adetayo Kasim, Adrian Mellor 1., Khalid Khan, Gavin Murphy \& James Mason (2017): Manubrium-limited ministernotomy versus conventional sternotomy for aortic valve replacement (MAVRIC): study protocol for a randomised controlled trial. Trials 18:46

3. Bjørnnes A., Lie I., Parry M., Falk R., Leegaard M., (2018): Association between selfperceived pain sensitivity and pain intensity after cardiac surgery, Journal of Pain Research, 11:1425-1432.

4. Cakir H., Ismail Y., Koksal D., Hasan I., Ihsan P., (2018): Risk models for patients undergoing robotic surgery, minimal invasive heart surgery and open-heart surgery,Medicine Science international medical journal,7(4):959-6.

5. Cheng D., Jant Martin, AvtarLal, Anno Diegeler, Thierry A., Folliguet, Wiley Nifong, Patrick Perier, Ehud Raanani, Michael Smith, Joerg Seeburger \& Volkmar Falk, (2011): Minimally invasive versus conventional open mitral valve surgery.(Inovations;6:84-103)

6. Kenan A., Zafer E., Aytuğ K., Şenol G., Ahmet Ö., (2017): Comparison between two sternum 
closing techniques by median sternotomy during open cardiac surgery, journal of cardiovascular medicine,5(3):44-49.

7. Lars G., Fernando A., Delos M., Eugene H., Jeevanantham R., (2014): Minimally invasive versus conventional mitral valve surgery: A propensity-matched comparison, The Journal of Thoracic and Cardiovascular Surgery, 139(4): 926-932.

8. Mark A., Ramón A., Fluder E., Sawicki K., \& Mihail P., (2016): Port-access Minimally Invasive Cardiac Surgery Increases Surgical Complexity, Increases Operating Room Time, and Facilitates Early Postoperative Hospital Discharge, American Society of Anesthesiologists, 92:1637-1645.

9. Michael E., Dawn S., John D., Wendy J., Raina S., (2016): A comparison of aortic valve replacement via an anterior right minithoracotomy with standard sternotomy: a propensity score analysis of 492 patients, European journal of Cardio-Thoracic Surgery,49(2): 456-463.

10. Paul T., Mark O., Jeffrey G., Carmelo A., Mark S., (2015): Right Minithoracotomy Versus Median Sternotomy for Mitral Valve Surgery: A Propensity Matched Study,Annals of thoracic Surgery 100(2):575-581.

11. Rakesh M., Ryan M., Harold M., Huebner M., Zhuo L., (2012): quality of life after early mitral valve repair using conventional and robotic approaches, The Society of Thoracic Surgeons, Elsevier.

12. Rosengart T., Feldman T., Borger M., Vassiliades T., Gillinov A., Hoercher K., (2008): Percutaneous and minimally invasive valve procedures: a scientific statement from the American Heart Association Council on Cardiovascular Surgery and Anesthesia, Council on Clinical Cardiology, Functional Genomics and Translational Biology Interdisciplinary Working Group, and Quality of Care and Outcomes Research Interdisciplinary Working Group. Circulation;117(13):1750-67.

13. Saif U., Chitradeep D., William M., \& Joseph T., (2018): Minimally Invasive Cardiac Surgery vs Conventional Coronary Artery Bypass Grafting: A comparison of outcomes and cost, The International Society for Minimally Invasive Cardiothoracic Surgery.

14. Schweikert B., Harry W., \& Reiner L., (2016): Validation of the Euro Qol questionnaire in cardiac rehabilitation, Heart (British Cardiac Society) 92(1):62-7.

15. Shawky F., Waleed A., Mohamed S., Ahmed F., Ayman S., (2016): Early outcome of minimally invasive mitral valve surgery, Journal of the Egyptian Society of Cardio-Thoracic Surgery, 24(2):173-180.

16. Speziale G., Khalil Fattouch, Vito Romano, Mauro Del Giglio, Alberto Albertini, Chiara Comoglio, Renato Gregorini, Roberto Coppola, Roberta Spirito, Georges Popoff, and Giuseppe Nasso (2015): Minimally invasive mitral valve surgery: state-of-the-art and our experience. European Heart Journal Supplements 17 (Supplement A), A49-A53

17.Stephens R., Glenn J., (2015): Whitman Postoperative Critical care of the adult cardiac surgical patient .(WWW.Comjournal.Org)

18. Svensson G., Fernando A., Delos M., Eugene H., Jeevanantham R., (2015): Minimally invasive versus conventional mitral valve surgery: A propensity-matched comparison, The Journal of Thoracic and Cardiovascular Surgery,139(4): 926-932.

19. Thomas W., Volkmar F., Sebastian M., Anno D,Roberto B., (2015): Pain and quality of life after minimally invasive versus conventional cardiac surgery,annals of thoracic surgery journal, 67(6):1643-1647.

20. Ward A., Grossi E., \& Galloway A., (2013): Minimally invasive mitral surgery through right mini-thoracotomy under direct vision, Journal of Thoracic Diseases, 5:673-679.

21. Yamada T., Ryoichi O., Junzo T., Hankei S., \& Ryohei Y., (2013): Comparison of early postoperative quality of life in minimally invasive versus conventional valve surgery, journal of anesthesia, 17:171-176.

22. Yamada T., Ryoichi O., Junzo T., Hankei S., \& Ryohei Y., (2013): Comparison of early postoperative quality of life in minimally invasive versus conventional valve surgery, journal of anesthesia, 17:171-176. 